\title{
The tryptophan requirement of the kitten
}

\author{
BY DIANE M. HARGROVE, QUINTON R. ROGERS \\ AND JAMES G. MORRIS \\ Departments of Physiological Sciences and Animal Sciences, University of California, \\ Davis, California 95616, USA
}

(Received 14 March 1983 - Accepted 12 May 1983)

1. To estimate the tryptophan requirement of the kitten, six male and six female kittens were presented diets containing $0.7,0.9,1.1,1.3,1.5$ and $3.0 \mathrm{~g}$ tryptophan $/ \mathrm{kg}$ diet for six experimental periods lasting $10 \mathrm{~d}$ in accordance with a $6 \times 6$ balanced Latin-square design.

2. Mean daily weight gain and nitrogen retention ( $N$ intake minus urinary and faecal $N$ ) plateaued at $1.1 \mathrm{~g}$ tryptophan $/ \mathrm{kg}$ diet indicating that the minimal tryptophan requirement of the kitten was $1 \cdot 1 \mathrm{~g} / \mathrm{kg}$ diet.

3. Plasma tryptophan concentration exhibited a marked increase at dietary tryptophan concentrations above $1.3 \mathrm{~g} / \mathrm{kg}$ diet.

The essentiality of tryptophan in the diet of growing kittens was shown by Rogers \& Morris (1979) who reported weight loss and depressed food intake in kittens whose diet was changed from one containing $4.0 \mathrm{~g}$ tryptophan $/ \mathrm{kg}$ diet to one devoid of tryptophan. They further reported that weight gain was not affected when kittens were given diets containing $4.0 v .2 .0 \mathrm{~g}$ tryptophan $/ \mathrm{kg}$ diet. Anderson et al. (1980) suggested that $1.5 \mathrm{~g} / \mathrm{kg}$ diet was the minimal tryptophan requirement for growth in kittens. This estimate was based on a $4 \times 4$ Latin-square-design experiment using four kittens given $0,1 \cdot 0,2.5$ or $4.0 \mathrm{~g}$ tryptophan $/ \mathrm{kg}$ diet and a randomized block design with groups of five kittens allotted to diets containing $0.5,1.5$ or $2.5 \mathrm{~g}$ tryptophan $/ \mathrm{kg}$ diet. In both experiments weight gain was the only factor measured. In the $4 \times 4$ Latin-square-design experiment maximal growth was attained at $2.5 \mathrm{~g}$ tryptophan $/ \mathrm{kg}$ diet which was significantly higher than the growth at $1.0 \mathrm{~g}$ tryptophan $/ \mathrm{kg}$ diet. In their second experiment maximal growth was attained at $1.5 \mathrm{~g}$ tryptophan $/ \mathrm{kg} \mathrm{diet}$, which they assumed was the tryptophan requirement.

The purpose of this report was to define more precisely the tryptophan requirement of the growing kitten based on weight gain and nitrogen balance and to examine whether plasma tryptophan concentrations could be used to estimate the tryptophan requirement.

\section{METHODS}

Animals

Specific-pathogen-free domestic short-hair kittens vaccinated against panleukopenia were given a semi-purified diet from weaning. A preliminary period of $10 \mathrm{~d}$ before the feeding of the experimental diets was used to adapt the kittens to the purified amino acid diet (Table 1). Six males and six females were selected on the basis of body-weights in the range of $900-1200 \mathrm{~g}$ and weight gains of at least $10 \mathrm{~g} / \mathrm{d}$ during the preliminary period. At the beginning of the feeding of the experimental diets the mean (and SD) body-weights were $1087(91) \mathrm{g}$ for the males and $1105(45) \mathrm{g}$ for the females. The kittens were housed individually in stainless-steel metabolism cages with food and water available ad lib.

Diets

Six isoenergetic and isonitrogenous diets containing $240 \mathrm{~g}$ crystalline amino acid mix $/ \mathrm{kg}$ were used. The energy contents of the diets per g dry matter (by analysis) were $22.7 \mathrm{~kJ}$ gross energy, $19 \cdot 3 \mathrm{~kJ}$ apparent digestible energy and $18.4 \mathrm{~kJ}$ apparent metabolizable energy. The 
Table 1. Composition of basal diet $(\mathrm{g} / \mathrm{kg}$ diet $)$

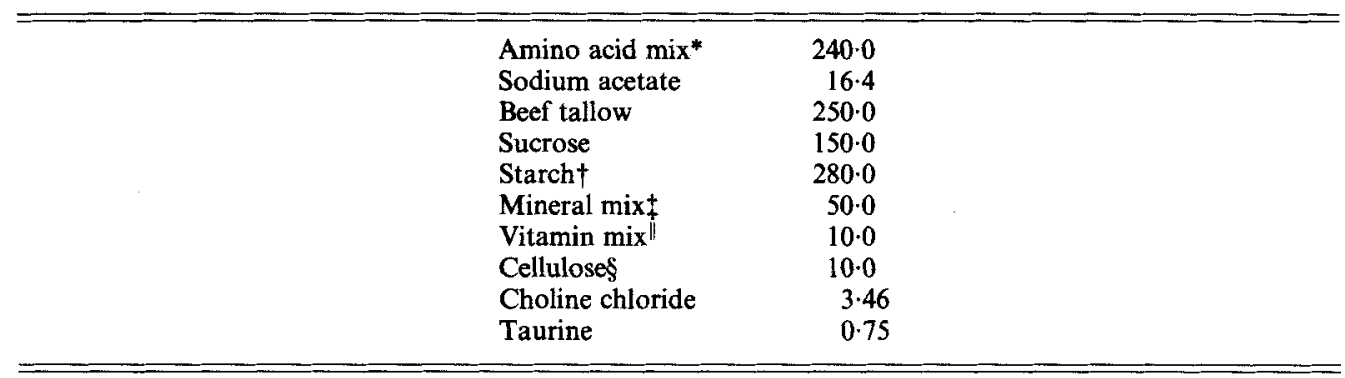

* Composition of amino acid mix (g/kg diet): Arg hydrochloride 20.0, Cys 6.0, Met 9.0, $\mathrm{His} \mathrm{HCl} . \mathrm{H} \mathrm{O}_{6} \cdot 0$,

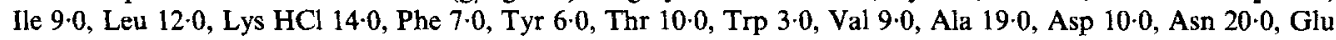
$20 \cdot 0$, Gin $30 \cdot 0$, Gly $20 \cdot 0$, Pro $10 \cdot 0$.

$\uparrow$ Melojel, food grade maize starch; National Starch and Chemical Company, Bridewater, New Jersey.

† Composition of mineral mix (g/kg mix): $\mathrm{CaHPO}_{4} 390 \cdot 0, \mathrm{CaCO}_{\mathrm{g}} 110 \cdot 0, \mathrm{MgSO}_{4} 45 \cdot 0, \mathrm{~K}_{2} \mathrm{HPO}_{4} 90 \cdot 0, \mathrm{KCl} 100 \cdot 0$, $\mathrm{KHCO}_{3} 100 \cdot 0, \mathrm{NaHCO}_{3} 140 \cdot 0$, trace minerals $25 \cdot 0$. Individual trace elements $(\mathrm{g} / \mathrm{kg}$ mineral mix $): \mathrm{MnSO}_{4} . \mathrm{H}_{2} \mathrm{O}$ 3.84, $\mathrm{ZnSO}_{4} \cdot 7 \mathrm{H}_{2} \mathrm{O} 4.45, \mathrm{CuSO}_{4} \cdot 5 \mathrm{H}_{2} \mathrm{O} 0.80$, ferric citrate $3 \mathrm{H}_{2} \mathrm{O} 10 \cdot 0$, pentacalcium orthoperiodate $0 \cdot 15$, $\mathrm{SnCl}_{2} .2 \mathrm{H}_{2} \mathrm{O} 0 \cdot 10, \mathrm{Na}_{2} \mathrm{SeO}_{3} 0 \cdot 03,\left(\mathrm{NH}_{4}\right)_{6} \mathrm{Mo}_{7} \mathrm{O}_{4} \cdot 4 \mathrm{H}_{2} \mathrm{O} 0 \cdot 04, \mathrm{CrCl}_{3} \cdot 6 \mathrm{H}_{2} \mathrm{O} 0 \cdot 26, \mathrm{NiCl}_{2} \cdot 6 \mathrm{H}_{2} \mathrm{O} 0 \cdot 30, \mathrm{NaF} 0 \cdot 14$, $\mathrm{NH}_{4} \mathrm{VO}_{3} .4 \mathrm{H}_{2} \mathrm{O} 0 \cdot 02$, carrier $(\mathrm{NaCl}) 4 \cdot 87$.

$\|$ Composition of vitamin $\operatorname{mix}(\mathrm{mg} / \mathrm{kg}$ diet): retinyl palmitate 80 , cholecalciferol 5, DL- $\alpha$-tocopherol 640 , menadione 15 , thiamine hydrochloride 25 , riboflavin 10 , pyridoxine 10 , nicotinic acid 100 , calcium pantothenate 20, myo-inositol 200, folic acid 10, cobalamin 50, biotin 1, ascorbic acid 400 , sucrose 8434 .

$\S$ Solka-Floc, wood cellulose; Brown \& Co. Berlin, New Hampshire, USA. Added to complete diet to facilitate faecal collection.

experimental diets were the same as the basal diet (Table 1) except that tryptophan was varied and alanine and starch were adjusted to make the diets isonitrogenous. All diets contained adequate levels of the essential amino acids (except tryptophan) to support normal growth (Rogers \& Morris, 1979). The tryptophan levels of the six experimental diets were $0.7,0.9,1 \cdot 1,1 \cdot 3,1.5$ and $3.0 \mathrm{~g}$ tryptophan $/ \mathrm{kg}$ diet.

\section{Design}

Six pairs of kittens consisting of one female and one male were assigned experimental diets for sequential $10 \mathrm{~d}$ periods in accordance with $6 \times 6$ balanced Latin square design (Cochran \& Cox, 1957) which allows for analysis of residual, period, animal and treatment effects.

Food intake and body-weight were recorded daily. Mean daily weight gain over the $10 \mathrm{~d}$ periods was determined by a least-squares regression analysis of daily body-weights. Urine acidified with sulphuric acid was collected daily and pooled in two separate $5 \mathrm{~d}$ collection periods to determine if there were any carry-over effects between experimental periods. Faeces were collected daily and pooled over the $10 \mathrm{~d}$ period. The $\mathrm{N}$ contents of food, urine and faeces were measured by the Kjeldahl procedure (Association of Official Agricultural Chemists, 1975). In $\mathrm{N}$ balance determinations, hair loss was disregarded.

\section{Plasma amino acid analysis}

On the 9th day of each experimental period, at 13.00-15.00 hours, $3 \mathrm{ml}$ blood samples were drawn with heparinized syringes from the jugular vein of unanaesthetized kittens and immediately placed on ice. Plasma was separated by centrifugation and frozen $\left(-80^{\circ}\right)$ until analysis. Samples were prepared for amino acid analysis by the addition of equal volumes of sulphosalicylic acid $(60 \mathrm{~g} / \mathrm{l})$, centrifuged to remove the protein precipitate, and adjustment of the filtrate to $\mathrm{pH} 2 \cdot 2$ with lithium hydroxide. An equivalent of $40 \mu 1$ plasma was applied to the amino acid analyzer (Model 121MB; Beckman Instrument, Palo Alto, CA). 
Table 2. Effect of dietary tryptophan level on weight gain, food intake and nitrogen retention

(Mean values with their standard errors for six kittens in the single sex groupings and for twelve kittens in the combined sex group)

\begin{tabular}{|c|c|c|c|c|c|c|c|}
\hline \multirow[b]{2}{*}{ Group } & \multirow{2}{*}{$\begin{array}{c}\text { Dietary } \\
\text { tryptophan } \\
(\mathrm{g} / \mathrm{kg})\end{array}$} & \multicolumn{2}{|c|}{ Wt gain $(\mathrm{g} / \mathrm{d})$} & \multicolumn{2}{|c|}{ Food intake $(\mathrm{g} / \mathrm{d})$} & \multicolumn{2}{|c|}{$\mathrm{N}$ retention $(\mathrm{g} / \mathrm{d})$} \\
\hline & & Mean & SE & Mean & SE & Mean & $\mathbf{S E}$ \\
\hline Males & $\begin{array}{l}0 \cdot 7 \\
0 \cdot 9 \\
1 \cdot 1 \\
1 \cdot 3 \\
1 \cdot 5 \\
3 \cdot 0\end{array}$ & $\begin{array}{l}10 \cdot 7^{a} \\
20 \cdot 2^{a b} \\
32 \cdot 0^{b} \\
27 \cdot 5^{b} \\
30 \cdot 1^{b} \\
30 \cdot 1^{b}\end{array}$ & $\begin{array}{l}2 \cdot 9 \\
2 \cdot 5 \\
5 \cdot 6 \\
4 \cdot 6 \\
3 \cdot 3 \\
3 \cdot 1\end{array}$ & $\begin{array}{l}58 \cdot 9^{a} \\
66 \cdot 4^{a} \\
75 \cdot 1^{a} \\
70 \cdot 6^{a} \\
71 \cdot 9^{a} \\
69 \cdot 5^{a}\end{array}$ & $\begin{array}{r}8 \cdot 2 \\
3 \cdot 7 \\
11 \cdot 5 \\
4 \cdot 8 \\
6 \cdot 2 \\
4 \cdot 2\end{array}$ & $\begin{array}{l}0 \cdot 33^{a} \\
0 \cdot 56^{a b} \\
0 \cdot 85^{b} \\
0 \cdot 84^{b} \\
0 \cdot 83^{b} \\
0.79^{b}\end{array}$ & $\begin{array}{l}0 \cdot 10 \\
0 \cdot 08 \\
0 \cdot 17 \\
0 \cdot 11 \\
0 \cdot 12 \\
0 \cdot 07\end{array}$ \\
\hline Females & $\begin{array}{l}0.7 \\
0.9 \\
1.1 \\
1.3 \\
1.5 \\
3.0\end{array}$ & $\begin{array}{l}9 \cdot 2^{a} \\
15 \cdot 9^{a b} \\
21 \cdot 9^{b} \\
18 \cdot 6^{a b} \\
22 \cdot 0^{b} \\
25 \cdot 4^{b}\end{array}$ & $\begin{array}{l}0 \cdot 4 \\
3 \cdot 0 \\
1 \cdot 2 \\
3 \cdot 8 \\
3 \cdot 1 \\
3 \cdot 2\end{array}$ & $\begin{array}{l}59 \cdot 5^{a} \\
62 \cdot 4^{a} \\
67 \cdot 2^{a} \\
62 \cdot 1^{a} \\
61 \cdot 5^{a} \\
61 \cdot 7^{a}\end{array}$ & $\begin{array}{l}4 \cdot 8 \\
2 \cdot 7 \\
3 \cdot 1 \\
5 \cdot 4 \\
4 \cdot 8 \\
5 \cdot 3\end{array}$ & $\begin{array}{l}0.32^{a} \\
0.49^{a b} \\
0.55^{a b} \\
0.63^{b} \\
0.54^{a b} \\
0.62^{b}\end{array}$ & $\begin{array}{l}0.05 \\
0.09 \\
0.03 \\
0.06 \\
0.08 \\
0.10\end{array}$ \\
\hline Sexes combined & $\begin{array}{l}0.7 \\
0.9 \\
1.1 \\
1.3 \\
1.5 \\
3.0\end{array}$ & $\begin{array}{l}10 \cdot 0 \\
18 \cdot 0^{a} \\
27 \cdot 0^{a} \\
23 \cdot 1^{a} \\
26 \cdot 0^{a} \\
27 \cdot 8^{a}\end{array}$ & $\begin{array}{l}1 \cdot 4 \\
2 \cdot 0 \\
3 \cdot 2 \\
3 \cdot 1 \\
2 \cdot 5 \\
2 \cdot 2\end{array}$ & $\begin{array}{l}59 \cdot 2^{a} \\
64 \cdot 4^{a} \\
71 \cdot 2^{a} \\
66 \cdot 3^{a} \\
66 \cdot 7^{a} \\
65 \cdot 6^{a}\end{array}$ & $\begin{array}{l}4 \cdot 5 \\
2 \cdot 3 \\
5 \cdot 8 \\
3 \cdot 7 \\
4 \cdot 1 \\
3 \cdot 4\end{array}$ & $\begin{array}{l}0 \cdot 32^{a} \\
0.52^{b} \\
0 \cdot 70^{c} \\
0 \cdot 73^{c} \\
0.69^{c} \\
0.70^{c}\end{array}$ & $\begin{array}{l}0.06 \\
0.06 \\
0.09 \\
0.07 \\
0.08 \\
0.06\end{array}$ \\
\hline
\end{tabular}

$a, b, c$ Values within the same column and sex grouping not sharing a common superscript letter were significantly different: $P<0 \cdot 05$.

\section{Statistical analysis}

Values for weight gain, $\mathbf{N}$ retention, food intake and plasma tryptophan were subjected to analysis of variance. When analysis of variance indicated significant differences between treatments $(P<0.05)$ the SNK multiple-range test (Steele \& Torrie, 1960) was used to determine which means were significantly different. Values for males and females were analysed separately and combined because previous results from this laboratory have shown significant differences between male and female kittens in daily weight gain, food intake and $\mathrm{N}$ retention (Schaeffer et al. 1982; Smalley et al. 1983). To determine the response relationships a least-squares linear regression was fitted to the increasing points of response to dietary tryptophan concentration. A straight line parallel to the $x$ axis was fitted to the mean of all the points after which the response had plateaued. The intersection of the two lines was used to indicate the minimal dietary requirement for maximal response.

\section{RESULTS}

The effects of dietary tryptophan on weight gain, $\mathrm{N}$ retention, food intake and plasma tryptophan are shown in Table 2 and Figs. 1-3. There were no significant residual effects in any of the factors measured. Differences in $\mathrm{N}$ retention between the first and second halves of each experimental period were not significant, hence the results are presented for each $10 \mathrm{~d}$ period.

\section{Weight gain}

Mean daily weight gain for the males given the $0.7 \mathrm{~g}$ tryptophan $/ \mathrm{kg}$ diet was less $(P<0.05)$ than at all other levels except $0.9 \mathrm{~g}$ tryptophan $/ \mathrm{kg}$ diet. At $0.9 \mathrm{~g}$ tryptophan $/ \mathrm{kg}$ diet the mean daily weight gain for the males was not significantly different $(P>0.05)$ than at any 


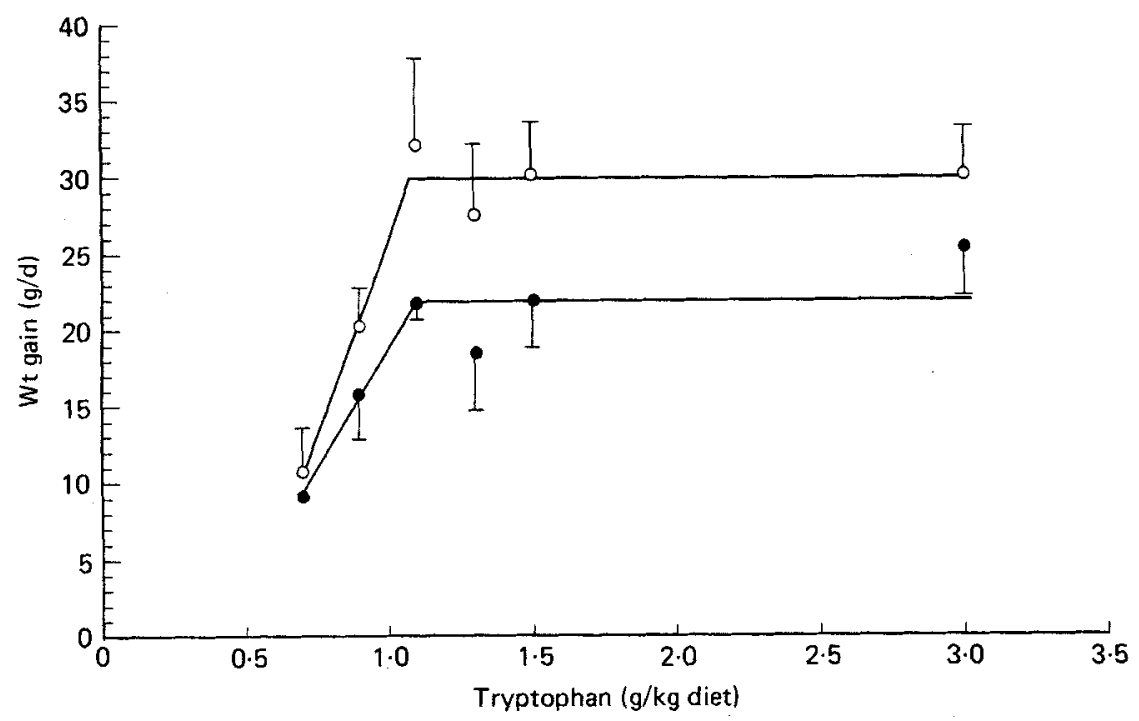

Fig. 1. The effect of dietary tryptophan on weight gain. Points represent mean values with their standard errors for six kittens: $(\mathrm{O}-\mathrm{O})$, males; $(-\mathrm{C})$, females.

other level. The female kittens showed a slightly different response. Their mean daily weight gain at $0.7 \mathrm{~g}$ tryptophan $/ \mathrm{kg}$ diet was significantly lower $(P<0.05)$ than at $1.1,1.5$ and $3.0 \mathrm{~g}$ tryptophan $/ \mathrm{kg}$ diet but was not different $(P>0.05)$ from the weight gains at 0.9 and $1.3 \mathrm{~g}$ tryptophan $/ \mathrm{kg}$ diet. Analysis of the mean daily weight gains for the sexes combined showed growth at $0.7 \mathrm{~g}$ tryptophan $/ \mathrm{kg}$ diet was significantly less $(P<0.05)$ than at all other levels of dietary tryptophan.

A plot of dietary tryptophan $v$. weight gain (Fig. 1) showed a linear increase in weight gain until $1.1 \mathrm{~g}$ tryptophan $/ \mathrm{kg}$ diet. At $1 \cdot 1 \mathrm{~g}$ tryptophan $/ \mathrm{kg}$ diet the weight gain plateaued at (mean and SD) $30(2) \mathrm{g} / \mathrm{d}$ for males and $22(3) \mathrm{g} / \mathrm{d}$ for females (values for weight gains from $1 \cdot 1$ to $3.0 \mathrm{~g}$ tryptophan $/ \mathrm{kg}$ diet). The break-point in the growth response curve indicated a tryptophan requirement of $1.1 \mathrm{~g}$ tryptophan $/ \mathrm{kg} \mathrm{diet.}$

\section{$N$ balance}

$\mathrm{N}$ balance results were similar to those for growth. For males, the $\mathrm{N}$ retained at $0.7 \mathrm{~g}$ tryptophan $/ \mathrm{kg}$ diet was lower $(P<0.05)$ than all other levels except at $0.9 \mathrm{~g}$ tryptophan $/ \mathrm{kg}$ diet. $\mathrm{N}$ retention for males at $0.9 \mathrm{~g}$ tryptophan $/ \mathrm{kg}$ diet was not significantly different $(P>0.05)$ from the $\mathrm{N}$ retention at any other level of dietary tryptophan. For the females the $\mathrm{N}$ retention at $0.7 \mathrm{~g}$ tryptophan $/ \mathrm{kg}$ diet was less $(P<0.05)$ than at 1.3 and $3.0 \mathrm{~g}$ tryptophan $/ \mathrm{kg}$ diet while the $\mathrm{N}$ retentions at $0.9,1.1$ and $1.5 \mathrm{~g}$ tryptophan $/ \mathrm{kg}$ diet were not significantly different from any of the other treatments. For the males and females combined, $\mathrm{N}$ retention at both 0.7 and $0.9 \mathrm{~g}$ tryptophan $/ \mathrm{kg}$ diet was significantly less than for the other treatment levels $(P<0.05)$.

The male and female $N$ retention response curves (Fig. 2) showed a linear increase in $N$ retention until $1.1 \mathrm{~g}$ tryptophan $/ \mathrm{kg}$ diet, after which the $\mathrm{N}$ retention plateaued at (mean and SD) $0.83(0.03) \mathrm{g} \mathrm{N} / \mathrm{d}$ for males and $0.59(0.05) \mathrm{g} \mathrm{N} / \mathrm{d}$ for females (values for $\mathrm{N}$ retentions from $1 \cdot 1$ to $3.0 \mathrm{~g}$ tryptophan $/ \mathrm{kg}$ diet). Although the females showed maximal $\mathrm{N}$ retention at $1.3 \mathrm{~g}$ tryptophan $/ \mathrm{kg}$ diet, there were no statistical differences in $\mathrm{N}$ retention for the dietary tryptophan range of $0.7-3.0 \mathrm{~g} / \mathrm{kg}$ diet $(P>0.05)$. The over-all $\mathrm{N}$ retention 


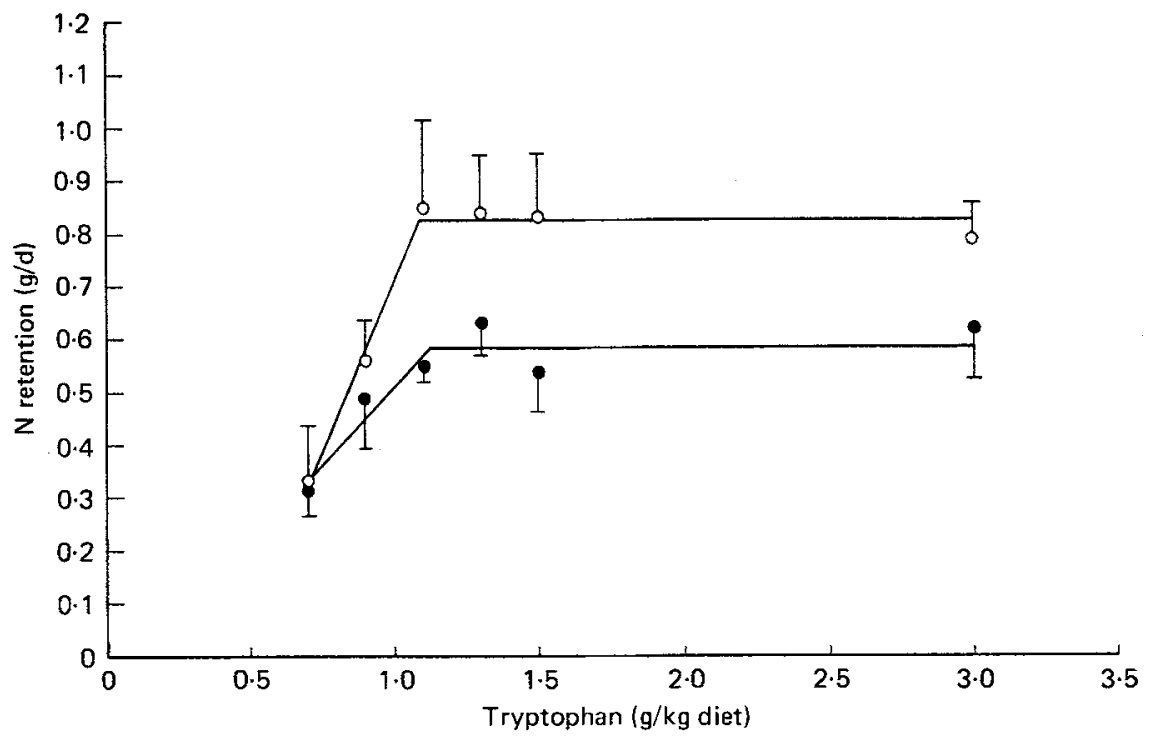

Fig. 2. The effect of dietary tryptophan on nitrogen retention. Points represent mean values with their standard errors for six kittens: $(\mathrm{O}-\mathrm{O})$, males; $\left(\mathrm{O}_{-}\right)$, females.

results supported the growth results indicating that $1.1 \mathrm{~g} / \mathrm{kg}$ diet was the tryptophan requirement.

\section{Food intake}

The level of dietary tryptophan had no significant effect $(P>0.05)$ on food intake. Females showed no significant period effects in food-intake. Male food intake was significantly higher $(P<0.05)$ in the last experimental period compared with all the other periods and food intake in the fifth period (second to last period) was greater than in the first period. Male food intake was greater than female food intake $(P<0 \cdot 01)$.

\section{Plasma tryptophan}

As there were no significant differences in the tryptophan concentration of the plasma between males and females $(P>0.05)$ a combined response curve was plotted. The combined values for tryptophan concentrations of plasma over the range of $0.7-1.3 \mathrm{~g}$ tryptophan $/ \mathrm{kg}$ diet were not significantly different $(P>0.05)$. These values were significantly less than the tryptophan concentrations of plasma from kittens given the diets containing 1.5 and $3.0 \mathrm{~g}$ tryptophan $/ \mathrm{kg} \operatorname{diet}(P<0.05)$. The response of plasma tryptophan to dietary tryptophan (Fig. 3) showed a break-point occurring between 1.3 and $1.5 \mathrm{~g}$ tryptophan $/ \mathrm{kg}$ diet. Maximal growth and $\mathrm{N}$ retention were attained before the break-point in plasma tryptophan.

\section{DISCUSSION}

Results for both $\mathrm{N}$ retention and growth indicated that $1 \cdot 1 \mathrm{~g}$ tryptophan $/ \mathrm{kg}$ diet was the minimal requirement for the growing kitten. Weight gain for both males and females and the $\mathrm{N}$ retention for males and the sexes combined increased linearly with increasing dietary tryptophan until $1.1 \mathrm{~g}$ tryptophan $/ \mathrm{kg}$ diet, after which the responses plateaued. The $\mathbf{N}$ retention values for the sexes combined gave a clear break-point both graphically and statistically at $1.1 \mathrm{~g}$ tryptophan $/ \mathrm{kg}$ diet with $\mathrm{N}$ retentions at 0.7 and $0.9 \mathrm{~g}$ tryptophan $/ \mathrm{kg}$ diet significantly lower $(P<0.05)$ than at the other treatment levels. 


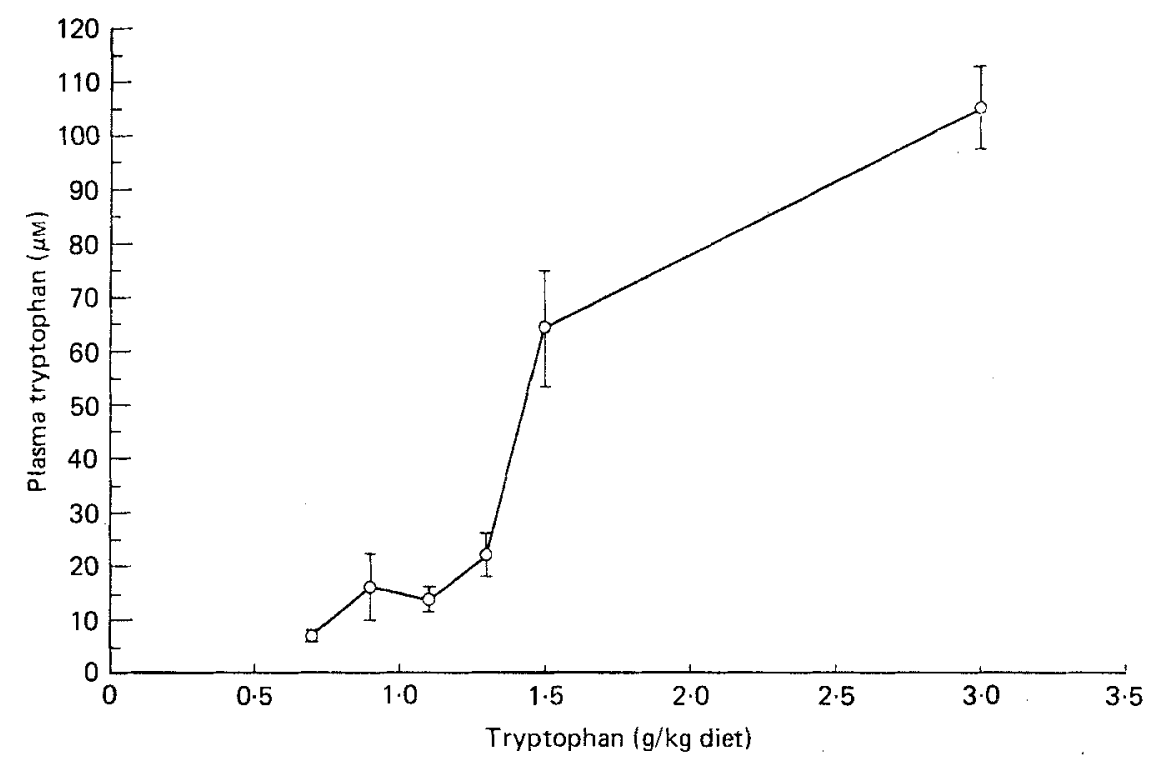

Fig. 3. The effect of dietary tryptophan on plasma tryptophan concentration. Points represent mean values with their standard errors for twelve kittens.

The results reported here showed a considerably lower tryptophan requirement for the kitten than the value of $1.5 \mathrm{~g}$ tryptophan $/ \mathrm{kg}$ diet reported by Anderson et al (1980) using greater increments of tryptophan in the diet. These authors did not state the sex of the kittens used in their experiments; growth was the only factor measured and the maximal growth of their kittens was suboptimal, being only $10-12 \mathrm{~g} / \mathrm{d}$ compared with $25-30 \mathrm{~g} / \mathrm{d}$ reported here.

The tryptophan requirements reported for other species are comparable with our value for the kitten. Tryptophan requirements reported for $35-60 \mathrm{~kg}$ swine ((US) National Research Council, 1979) and for rats (Rao et al. 1959) are the same as that reported here for the kitten. However, in the rat, reported values for the tryptophan requirement vary widely. Rao et al. (1959) attained maximal rat growth at $1 \cdot 1 \mathrm{~g}$ tryptophan $/ \mathrm{kg}$ diet. Young \& Munro (1973) reported maximal rat growth occurring between 1.1 and $1.65 \mathrm{~g}$ tryptophan $/ \mathrm{kg}$ diet and graphical interpolation of their results indicated maximal growth at $1.4 \mathrm{~g}$ tryptophan $/ \mathrm{kg}$ diet. Using plasma tryptophan, McLaughlan \& Illman (1967) indicated $1.3 \mathrm{~g}$ tryptophan $/ \mathrm{kg}$ diet as the requirement for the young rat. The (US) National Research Council (1978) suggested $1.5 \mathrm{~g}$ tryptophan $/ \mathrm{kg}$ diet as the requirement for the growing rat.

In the present study the break-point in plasma tryptophan occurred at a dietary tryptophan level higher than that required for maximal growth and $\mathbf{N}$ retention. In a study using young rats, Young \& Munro (1973) showed maximal growth and the break-point in plasma tryptophan concentration occurred between 1.1 and $1.65 \mathrm{~g}$ tryptophan $/ \mathrm{kg}$ diet. Although these authors concluded that the plasma tryptophan break-point occurred before maximal growth, based on the values presented it could not be established whether the plasma break-point occurred before or after maximal growth because no levels of tryptophan between 1.1 and $1.65 \mathrm{~g}$ tryptophan $/ \mathrm{kg}$ diet were tested.

Feline tryptophan metabolism differs from that of most other mammalian species as there is very little conversion of tryptophan to niacin. Carvalho da Silva et al. (1952) showed that 
cats stopped growing, lost weight and eventually died when given a niacin-free diet containing excess tryptophan. Jackson (1939) showed that no kynurenic acid could be isolated from the urine of cats kept on a diet providing excess tryptophan. Work by Ikeda et al. (1965) indicated that cats have the enzymic capacity to synthesize niacin from tryptophan, but that the high activity of hepatic picolinic carboxylase (thirty to fifty times that of the rat) is responsible for the cat's inability to convert appreciable amounts of tryptophan to niacin.

The results reported here strongly suggest $1.1 \mathrm{~g}$ tryptophan $/ \mathrm{kg}$ diet as the minimal requirement of the kitten for maximal growth and $\mathrm{N}$ retention.

The authors wish to thank Katherine Smalley for her advice and assistance throughout the experiment, Dan Wong for assistance with the plasma amino acids analysis, Ajinomoto Inc. USA for generously supplying part of the amino acids and Hoffman-La Roche Inc. Nutley, New Jersey for providing the vitamin mix. This research was supported in part by a grant from the Pet Food Institute, Washington, DC.

\section{REFERENCES}

Anderson, P. A., Baker, D. H., Sherry, P. A. \& Corbin, J. E. (1980). Journal of Animal Science 50, 479-483.

Association of Official Agricultural Chemists (1975). Official Methods of Analysis, 12th ed., Washington, DC: Association of Official Agricultural Chemists.

Carvalho da Silva, A., Fried, R. \& de Anelis, C. R. (1952). Journal of Nutrition 46, 399-409.

Cochran, W. G. \& Cox, G. M. (1957). Experimental Designs, 2nd ed. New York: John Wiley \& Sons, Inc.

Ikeda, M., Tsuji, H., Shigenobu, N., Ichiyama, A., Nishizuka, Y. \& Hayaishi, O. (1965). Journal of Biological Chemistry 240, 1395-1401.

Jackson, R. W. (1939). Journal of Biological Chemistry 131, 469-478.

McLaughlan, J. M. \& Illman, W. I. (1967). Journal of Nutrition 93, 21-24.

National Research Council (1978). Nutrient Requirements of Domestic Animals no. 10, Nutrient Requirements of Laboratory Animals, 3rd revised ed. Washington, DC: National Academy of Science-National Research Council.

National Research Council (1979). Nutrient Requirements of Domestic Animals no. 2, Nutrient Requirements of Swine, 8th revised ed., Washington, DC: National Academy of Science-National Research Council.

Rao, P. B. R., Metta, V. C. \& Johnson, B. C. (1959). Journal of Nutrition 69, 387-391.

Rogers, Q. R. \& Morris, J. G. (1979). Journal of Nutrition 109, 718-723.

Schaeffer, M. C., Rogers, Q. R. \& Morris, J. G. (1982). Journal of Nutrition 112, 962-971.

Smalley, K. A., Rogers, Q. R., Morris, J. G. (1983). British Journal of Nutrition 49, 41 1-417.

Steele, R. \& Torrie, J. H. (1960). The Principles and Procedures of Statistics. New York: McGraw Hill Book Company Inc.

Young, V. R. \& Munro, H. N. (1973). Journal of Nutrition 103, 1756-1763. 